\title{
Risk of colorectal cancer associated with the methylenetetrahydrofolate reductase (MTHFR) C677T polymorphism in the Kashmiri population
}

\author{
A.S. Sameer ${ }^{1,2}$, Z.A. Shah ${ }^{1}$, S. Nissar ${ }^{1}$, S. Mudassar ${ }^{2}$ and M.A. Siddiqi ${ }^{1}$ \\ ${ }^{1}$ Department of Immunology and Molecular Medicine, \\ Sher-I-Kashmir Institute of Medical Sciences, Kashmir, India \\ ${ }^{2}$ Department of Clinical Biochemistry, \\ Sher-I-Kashmir Institute of Medical Sciences, Kashmir, India \\ Corresponding author: M.A. Siddiqi \\ E-mail: vc.tmuk@gmail.com
}

Genet. Mol. Res. 10 (2): 1200-1210 (2011)

Received September 20, 2010

Accepted February 17, 2011

Published June 21, 2011

DOI 10.4238/vol10-2gmr1067

\begin{abstract}
Methylenetetrahydrofolate reductase (MTHFR) is a critical enzyme in folate metabolism and is involved in DNA synthesis, DNA repair and DNA methylation. The two common functional polymorphisms of MTHFR, $677 \mathrm{C} \rightarrow \mathrm{T}$ and $1298 \mathrm{~A} \rightarrow \mathrm{C}$, have been shown to impact various diseases, including cancer. The $677 \mathrm{C} \rightarrow \mathrm{T}$ polymorphism has been widely investigated in different cancers and has been implicated as a risk factor for the development of various cancers. We investigated MTHFR C677T genotype frequency in colorectal cancer cases in the Kashmiri population and correlated this information with the known clinicopathological characters of colorectal cancer, in a case-control study. Eighty-six colorectal cancer cases were studied for MTHFR C677T polymorphism, compared to 160 controls taken from the general population, employing the PCR-RFLP technique. We found the frequency of the three different genotypes of MTHFR in our ethnic Kashmir population, i.e., CC, CT and TT, to be
\end{abstract}


68.6, 20.9 and $10.4 \%$ among colorectal cancer cases and 75.6, 16.9 and $7.5 \%$ among the general control population, respectively. There was a significant association between the MTHFR TT genotype and colorectal cancer in the higher age group. We conclude that the MTHFR C677T polymorphism slightly increases the risk for colorectal cancer development in our ethnic Kashmir population.

Key words: Colorectal cancer; MTHFR; Polymorphism; RFLP; Restriction digestion; Kashmir

\section{INTRODUCTION}

Colorectal cancer (CRC) is the third most commonly diagnosed cancer and the third leading cause of cancer death in the world (Center et al., 2009a,b). The incidence of this malignancy shows considerable variation among racially or ethnically defined populations in multiracial/ethnic countries. Colorectal cancer is the third most common cancer in men and the second most common cancer in women worldwide (Jemal et al., 2011). To date, Kashmir has been reported as a high-incidence area of gastrointestinal (GIT) cancers (Mir et al., 2005; Murtaza et al., 2006). In Kashmir Valley, CRC represents the third most common GIT cancer after esophageal and gastric (Sameer et al., 2010a,b).

Methylenetetrahydrofolate reductase $(M T H F R)$ is a key enzyme regulating the metabolism of folates, which are important nutrients required for both DNA synthesis and DNA methylation (Lucock, 2000; Cicek et al., 2004). MTHFR irreversibly converts 5,10-methylenetetrahydrofolate to 5-methyltetrahydrofolate, the predominant circulating folate and the onecarbon donor for remethylation processes (Bailey and Gregory III, 1999).

Two common functional polymorphisms have been defined in the MTHFR gene - one is $C 677 T$ and other $A 1298 C$. MTHFR C677T polymorphism is the most important one regulating the function of this enzyme. This polymorphism results in an alanine-to-valine substitution at codon 222 of the protein (Frosst et al., 1995). This polymorphism has a profound effect on the MTHFR protein, not only does it decrease the thermal stability of this enzyme but also reduce its activity (Cicek et al., 2004). Individuals with the variant Val/Val genotype (TT) have no more than $30 \%$ of normal enzyme activity, and heterozygotes (CT) have $65 \%$ of normal enzyme activity (Frosst et al., 1995; Kono and Chen, 2005). This substitution also results in lower levels of 5-methyltetrahydrofolate, an accumulation of 5,10-methylenetetrahydrofolate and increased plasma homocysteine levels (Frosst et al., 1995; Ma et al., 1997; Bagley and Selhub, 1998).

Several studies from around the globe have reported on the association of MTHFR C677T polymorphism with the risk of colorectal carcinoma. While many studies have found the homozygous TT variant form to be inversely associated with the risk of colorectal carcinoma (Ma et al., 1997; Chen et al., 1996, 1998; Slattery et al., 1999; Houlston and Tomlinson, 2001; Marugame et al., 2003), others have reported lack of any association (Sachse et al., 2002; Shannon et al., 2002) or have associated the TT variant form with an increased risk of developing CRC (Park et al., 1999; Levine et al., 2000; Yin et al., 2004).

Therefore, we carried out a case-control study in our population to determine if this MTHFR C677T polymorphism is associated with an altered risk of developing CRC, as many 
dietary habits (Siddiqi et al., 1992; Mir et al., 2005; Murtaza et al., 2006; Sameer et al., 2010b) of our population have already been established as risk factors for the development of GIT cancers. We also investigated whether there is a link between these risk factors and the MTHFR C677T genotype and CRC predisposition.

\section{MATERIAL AND METHODS}

\section{Study population}

This study included 86 consecutive primary CRC patients. All CRC patients were recruited from the Department of Surgery, Sher-I-Kashmir Institute of Medical Science from March 2008 to August 2009. Tumor types and stages were determined by two experienced pathologists. Blood samples of 160 age- and gender-matched cases with no signs of any malignancy were collected for controls. The mean age of both patient and control groups was 52 years old, and 56 patients and 104 controls were $>50$ years or older. See Table 1 for details.

Data on all CRC patients were obtained from personal interviews with patients and or guardians, medical records and pathology reports. The data collected included gender, age, dwelling, tumor location, Dukes stage, lymph node status, pesticide exposure, and rectal bleeding. All patients and or guardians were informed about the study and their consent to participate in this study was taken on predesigned questionnaire (available on request). The collection and use of tumor and blood samples for this study were previously approved by the appropriate Institutional Ethics Committee.

\section{DNA extraction and polymerase chain reaction-restriction fragment length polymorphism (PCR-RFLP)}

DNA extraction was performed using any one of the previously described techniques. Previously reported primers, forward primer 5'-GGTCAGAAGCATATCAGTCAT GAG-3' and the reverse primer 5'-CTGGGAAGAACTCAGCGAACTCAG-3' (Cicek et al., 2004), were used for the amplification of the 494-bp target region within the MTHFR gene.

PCR was carried out in a final volume of $25 \mu \mathrm{L}$ containing $50 \mathrm{ng}$ genomic DNA template, 1X PCR buffer (Biotools) with $2 \mathrm{mM} \mathrm{MgCl}_{2}, 0.4 \mu \mathrm{M}$ of each primer (Genescript), $50 \mu \mathrm{M}$ dNTPs (Biotools), and 0.5 U DNA polymerase (Biotools). For PCR amplification, the standard program was used as follows: one initial denaturation step at $94^{\circ} \mathrm{C}$ for $7 \mathrm{~min}$, followed by 35 cycles of denaturation for $30 \mathrm{~s}$ at $94^{\circ} \mathrm{C}, 30 \mathrm{~s}$ of annealing at $58^{\circ} \mathrm{C}$, and $30 \mathrm{~s}$ of extension at $72^{\circ} \mathrm{C}$, followed by a final elongation cycle at $72^{\circ} \mathrm{C}$ for $5 \mathrm{~min}$. For RFLP, the PCR product of MTHFR was digested with $\operatorname{HinfI}\left(2 \mathrm{U}\right.$ at $37^{\circ} \mathrm{C}$ for $16 \mathrm{~h}$ ) (Fermentas). In the case of MTHFR C677T polymorphism, the wild-type Ala/Ala (CC) was identified by 394and 100-bp bands, while the Val/Val (TT) variant was identified by 229-, 165- and 100-bp bands and the heterozygous Ala/Val (CT) variant displayed all four bands $(394,229,165$, and $100 \mathrm{bp}$ ) (Figure 1).

DNA fragments were electrophoresed through a 2-3\% agarose gel for resolution. The genotypes of $>20 \%$ of the samples were double blindly reassessed to confirm the results by two independent researchers. A positive control for each polymorphism was used for $50 \%$ of samples. 


\section{Statistical analysis}

Observed frequencies of genotypes in CRC were compared to controls using chisquare or Fisher exact tests when expected frequencies were small. The chi-square test was used to determine whether genotype distributions were in Hardy-Weinberg equilibrium. Statistical significance was set at $\mathrm{P}<0.05$. Statistical analyses were performed using the PASW version 18 software.

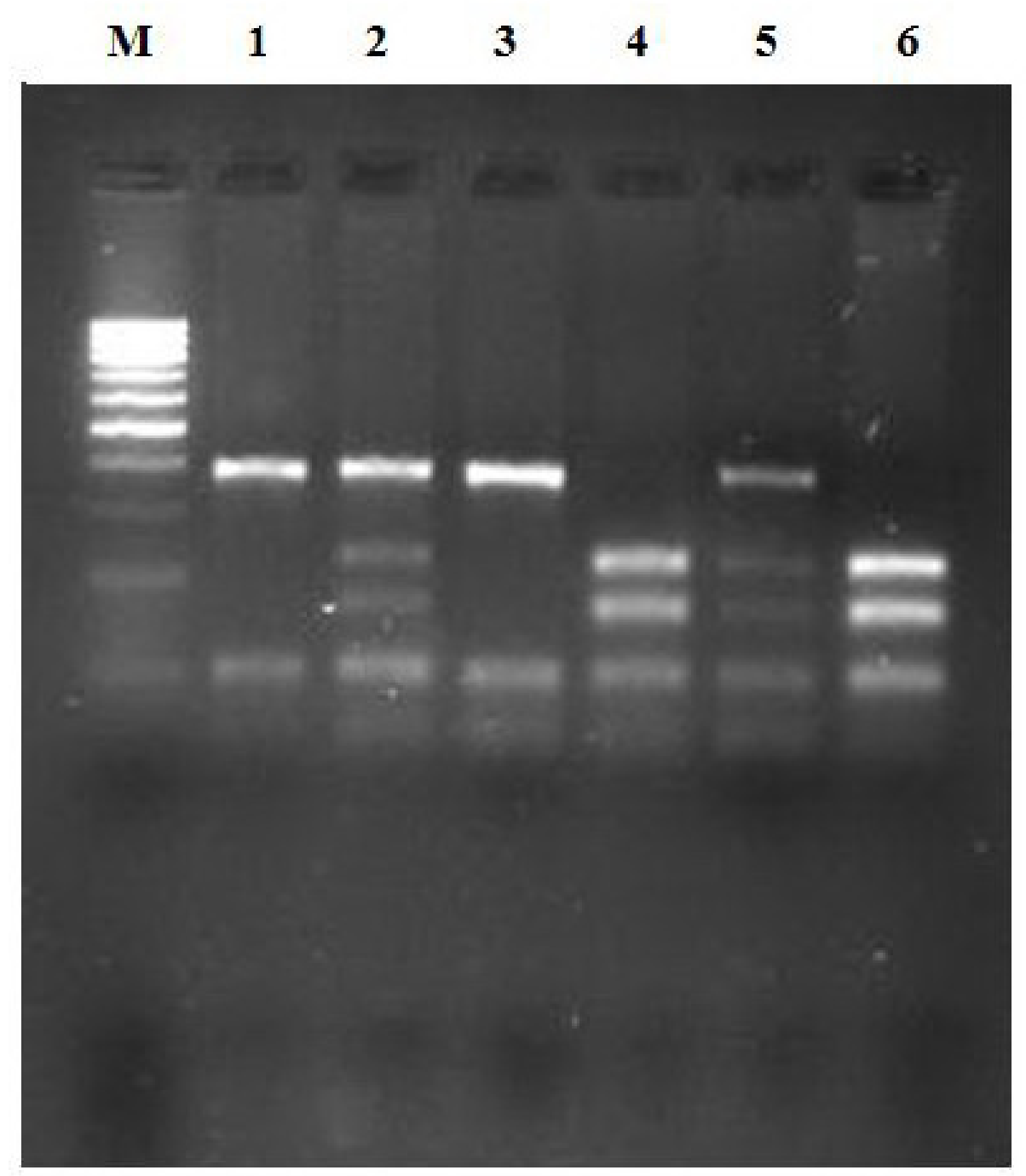

Figure 1. Representative gel of MTHFR C677T polymorphism, representing amplicon digest with HinfI (G|ANTC/ CTNA $\mid \mathrm{G})$; where the variant TT is cleaved but not the wild-type CC. Lane $M=100$-bp ladder. Lanes 1 and $3=$ wild-type (CC) form (394 and 100 bp). Lanes 2 and $5=$ heterozygous (CT) variant form (394, 229, 165, and 100 bp). Lanes 4 and $6=$ homozygous (TT) variant form (229, 165 and $100 \mathrm{bp})$. 


\section{RESULTS}

A total of 86 CRC patients and 160 control subjects were included in this study. The patients comprised 49 males and 37 females $(\mathrm{M} / \mathrm{F}$ ratio $=1.32)$ and the control subjects consisted of 88 males and 72 females $(M / F$ ratio $=1.2)$. Mean age in patient and control groups was 52 years. No significant gender- or age-related differences were observed between the groups $(\mathrm{P}>0.05)$. Furthermore, of 86 confirmed cases of CRC, 81 cases were sporadic, 4 were familial adenomatous polyposis (FAP) and one case was hereditary non-polyposis colorectal cancer (HNPCC). All cases were adenocarcinoma except one of squamous cell carcinoma (SCC) of the basal cell type; 59 were rural and 27 urban; 36 cases had carcinoma in the colon and 50 in the rectum, and 55 were smokers and 31 nonsmokers (Table 1).

\begin{tabular}{|c|c|c|c|}
\hline Variable & Cases $(\mathrm{N}=86)$ & Controls $(N=160)$ & $\mathrm{P}$ \\
\hline \multicolumn{4}{|c|}{ Age group (years) } \\
\hline$\leq 50$ & $30(34.9 \%)$ & $56(35.0 \%)$ & \multirow[t]{2}{*}{1.00} \\
\hline$>50$ & $56(65.1 \%)$ & $104(65.0 \%)$ & \\
\hline \multicolumn{4}{|l|}{ Gender } \\
\hline Female & $37(43.0 \%)$ & $72(45.0 \%)$ & \multirow[t]{2}{*}{0.764177} \\
\hline Male & $49(67.0 \%)$ & $88(55.0 \%)$ & \\
\hline \multicolumn{4}{|l|}{ Dwelling } \\
\hline Rural & $59(68.6 \%)$ & $104(65.0 \%)$ & \multirow[t]{2}{*}{0.565659} \\
\hline Urban & $27(31.4 \%)$ & $56(35.0 \%)$ & \\
\hline \multicolumn{4}{|c|}{ Smoking status } \\
\hline Never & $31(36.0 \%)$ & $75(46.8 \%)$ & \multirow[t]{2}{*}{0.102256} \\
\hline Ever & $55(64.0 \%)$ & $85(53.2 \%)$ & \\
\hline \multicolumn{4}{|c|}{ Pesticide exposure } \\
\hline Never & $33(38.4 \%)$ & $75(46.8 \%)$ & \multirow[t]{2}{*}{0.200325} \\
\hline Ever & $53(61.6 \%)$ & $85(53.2 \%)$ & \\
\hline
\end{tabular}

Data are reported as numbers with percent in parentheses.

In our study, we also found a varied difference in the genotype frequency of MTHFR C677T between CRC cases and the matched controls. The incidence of the MTHFR Val allele was increased in patients with CRC compared with healthy controls (Table 2). The frequency of Ala/Val (CT) genotype in CRC cases was $20.9 \%$ and that of Val/Val (TT) was $10.4 \%$, as compared to healthy controls, where it was 16.9 and $7.5 \%$, respectively. The overall hazard ratio of the MTHFR Val allele in patients with CRC was $1.41(95 \% \mathrm{CI}=0.79$ 2.54). Overall, both the heterozygous $\mathrm{CT}$ genotype (Ala/Val) and the homozygous variant TT genotype (Val/Val) were associated with a modestly elevated risk for CRC (OR $=1.36$; $95 \% \mathrm{CI}=0.70-2.67$ and $\mathrm{OR}=1.53 ; 95 \% \mathrm{CI}=0.61-3.85$, respectively). The overall hazard ratio for the $\mathrm{T}$ allele was $1.41(95 \% \mathrm{CI}=0.79-2.54)$ (Table 2$)$.

The correlation of MTHFR C677T polymorphic status with the clinicopathological characteristics was carefully analyzed. It was found that the Val/Val variant status increased the risk of CRC in the higher age group, smokers and the site of the tumor but not with the other variables (Table 3). 
Table 2. Genotype frequencies of MTHFR C677T gene polymorphism in cases and controls and their associations with the risk of colorectal cancer.

\begin{tabular}{lccc}
\hline MTHFR genotype & Cases $(\mathrm{N}=86)$ & Controls $(\mathrm{N}=160)$ & OR $(95 \% \mathrm{CI})$ \\
\hline Ala/Ala (CC) & $59(68.6 \%)$ & $121(75.6 \%)$ & 1.00 (Ref.) \\
Ala//Val (CT) & $18(20.9 \%)$ & $27(16.9 \%)$ & $1.36(0.70-2.67)$ \\
Val/Val (TT) & $9(10.4 \%)$ & $12(7.5 \%)$ & $1.53(0.61-3.85)$ \\
Ala/Val (CT) + Val/Val (TT) & $27(31.3 \%)$ & $39(24.4 \%)$ & $1.41(0.79-2.54)$ \\
\hline
\end{tabular}

Data are reported as number with percent in parentheses.

\section{DISCUSSION}

This is the first study to report on the association of MTHFR genotype with the risk of development of CRC in our Kashmiri population. The Kashmir Valley is located in the northern part of India, walled by the mighty Himalayas, its unique ethnic population live in discrete temperate environmental conditions and have distinctive eating habits, which play an overwhelming role in the development of GIT cancers over the genetic factors (Murtaza et al., 2006; Salam et al., 2009; Sameer et al., 2010a,b). As previously reported (Siddiqi et al., 1992), the etiology and incidence of various GIT cancers in this population have been attributed to the probable exposure to nitroso compounds, amines and nitrates reported to be present in the local foodstuffs. The various unique eating habits of our population include the consumption of sun-dried and smoked fish and meat, dried and pickled vegetables, red chili, Hakh (a leafy vegetable of the Brassica family), and hot noon chai (salted tea) and are accompanied by Hukka (water pipe) smoking (Mir et al., 2005).

The MTHFR gene, located on $1 \mathrm{p} 36.22$, encompasses $19.3 \mathrm{~kb}$ of DNA and is composed of 11 exons. The gene codes for a 74.6-kDa protein of 656 amino acids (Saffroy et al., 2005). It is a cytosolic enzyme that catalyzes the conversion of 5,10-methylenetetrahydrofolate to 5-methylenetetrahydrofolate, a co-substrate for homocysteine remethylation to methionine with subsequent production of S-adenosyl methionine, the universal methyl donor in humans, required for DNA methylation. The methylation of homocysteine is catalyzed by the enzyme methionine synthase, which requires the co-factor vitamin B12. MTHFR is also linked to the production of dTMP via thymidylate synthase and to purine synthesis and, therefore, plays a role in the provision of nucleotides essential for DNA synthesis (Wagner, 1995). Thus, any defect in the MTHFR gene will be reflected in an imperfection in the methylation pattern of DNA as well as in its synthesis.

It has been suggested by Chen et al. (1996) that the low activity of MTHFR 677TT genotype is probably advantageous because it ensures an adequate thymidylate pool for DNA synthesis when the folate supply is sufficient. However, in the folate-depleted situation high activity of the $677 C C$ genotype may be disadvantageous because 5,10-methylenetetrahydrofolate is converted and the thymidylate pool is depleted as suggested by Keku et al. (2002). Also, as per Haghighi et al. (2009) increased risk for $677 T T$ versus $677 C C$ would be seen in the folate-depleted situation if aberrant DNA methylation is a primary mechanism.

In this study, we analyzed $86 \mathrm{CRC}$ patients in relation to 160 healthy controls in order to examine the role of the C677T SNP in the MTHFR gene in CRC risk in the Kashmiri population. Cancer patients and healthy control subjects were well-matched for age, gender, ethnic distribution, and tobacco use. We found the frequency of the three different genotypes of MTHFR in our ethnic Kashmir population, i.e., CC, CT and TT, to be 68.6, 20.9 and 10.4\% 
A.S. Sameer et al.

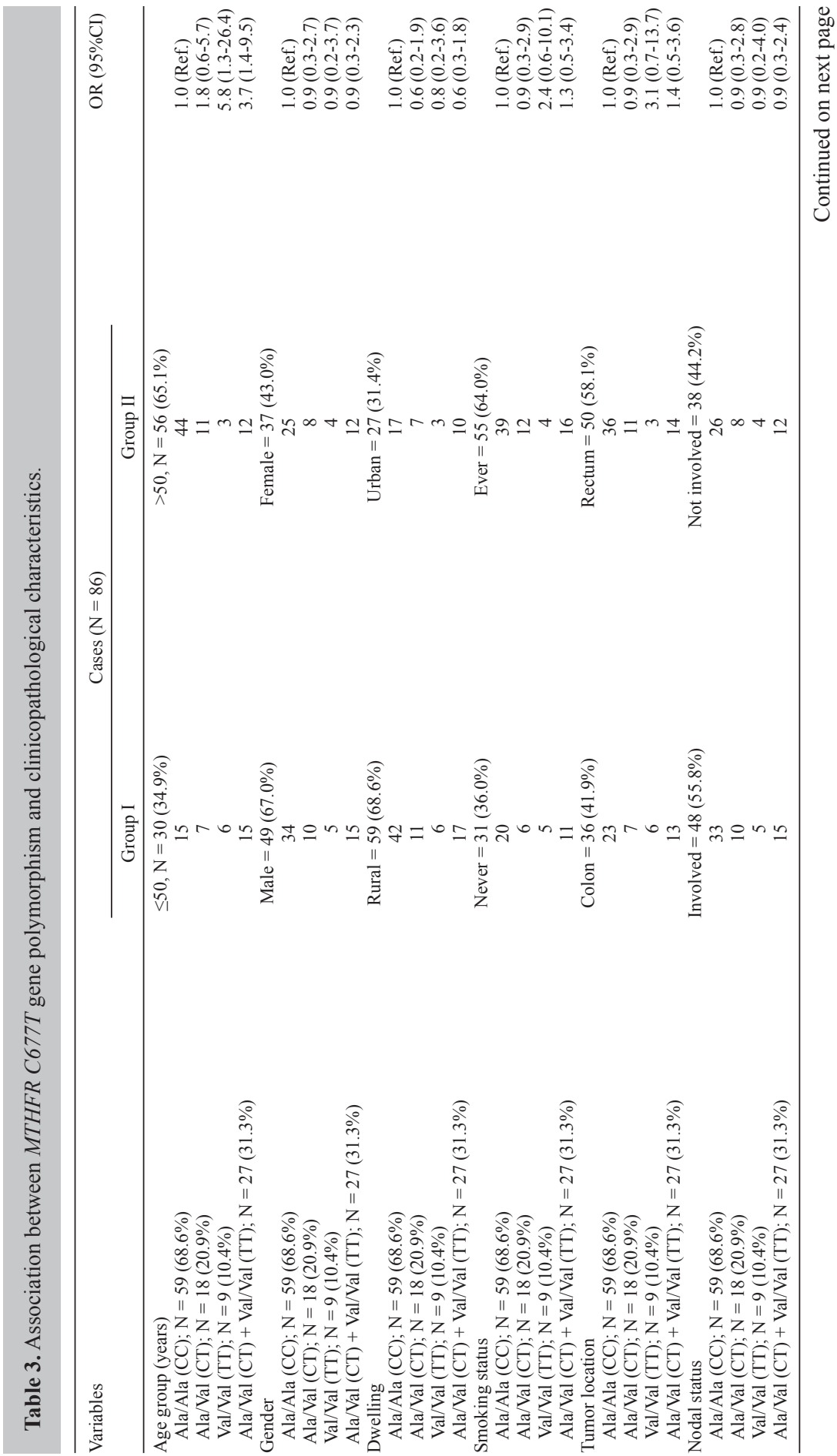

Genetics and Molecular Research 10 (2): 1200-1210 (2011) 


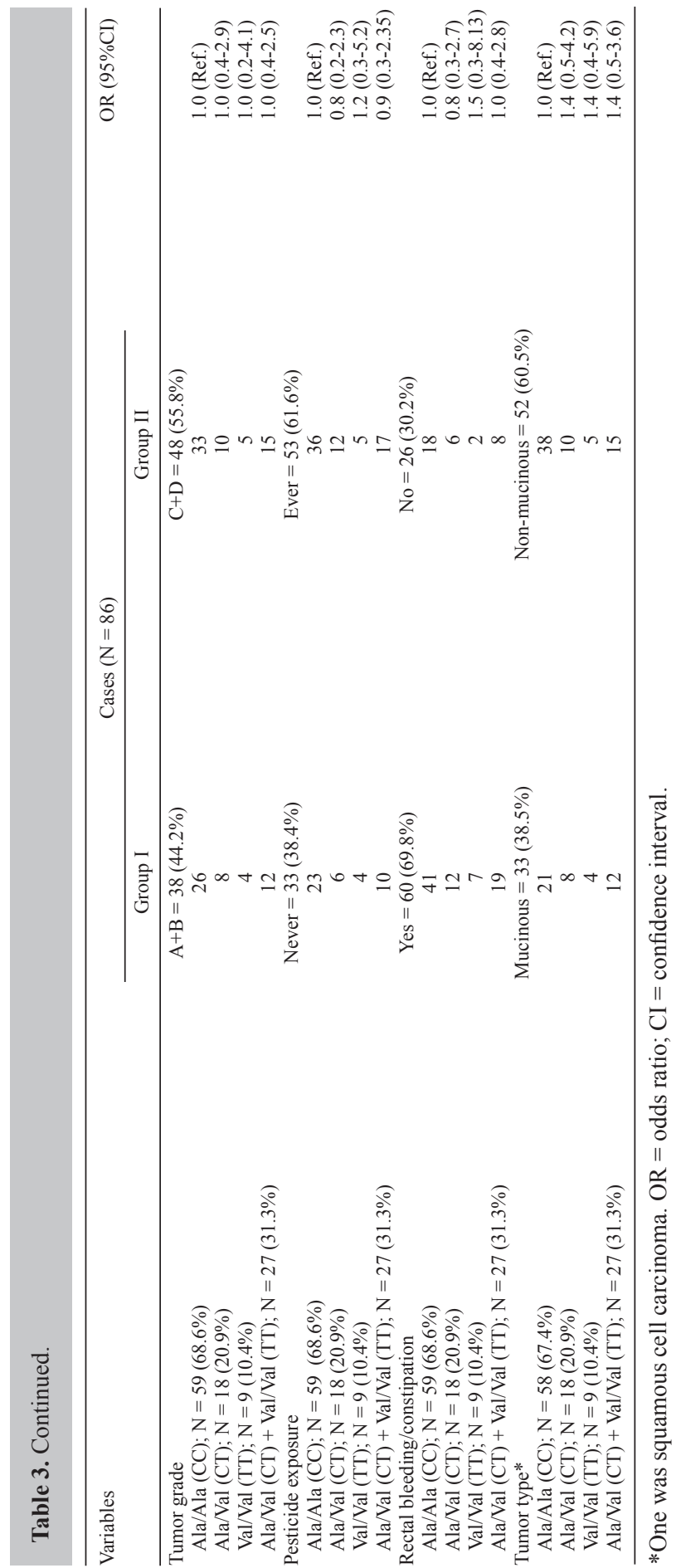


among CRC cases and 75.6, 16.9 and 7.5\% among the general control population, respectively. The results were similar to the previous study of Haghighi et al. (2009). This may be due to the fact that our population belongs to the same Persian genotypic pool as our ancestors have descended from the Persian migrants who have settled here during the 15th century.

Our results were somewhat different from the main Indian population (South), where the frequency of genotypes CC, CT and TT of MTHFR were reported to be 74, 25 and $1.0 \%$ among CRC cases and 76.7, 22.1 and 1.16\% in controls (Chandy et al., 2010). The difference in frequency may be due to ethnicity and the special set of environmental factors to which our population is exposed to (Sameer et al., 2010a,b).

Furthermore, we also found a 1.36-fold greater incidence of the MTHFR CT genotype and 1.53-fold greater incidence of the MTHFR TT genotype in patients with CRC compared with the healthy control population (Table 1).

In this case-control study, conducted for the first time in this population, we found a modest increase in the risk of CRC in the individuals with the TT (Val/Val) genotype when compared with the general population $(\mathrm{OR}=1.53 ; 95 \% \mathrm{CI}=0.61-3.85)$. These results were similar to previously reported studies (Ulrich et al., 1999; Shannon et al., 2002). These results also indicate that the MTHFR TT genotype, which is associated with lower functionality, does not play an avid protective role in the cell and also affects the methylation status of the cell by limiting the availability of 5,10-methylenetetrahydrofolate, which in turn, also affects thymidine synthesis.

We also found a significantly increased association of MTHFR TT (Val/Val) with age $(>50)(\mathrm{OR}=5.8 ; 95 \% \mathrm{CI}=1.3-26.4)$, indicating the deleterious role of decreased function of MTHFR in cell metabolism, where these results were in agreement with similar results reported by Shannon et al. (2002). We also found a modest increased risk of CRC with smoking status (ever), tumor location $(\mathrm{C}+\mathrm{D})$ and pesticide exposure (ever) $(\mathrm{OR}=2.4$; $3.1 ; 1.2$ ) (Table 3).

In a nutshell, this study revealed a significant correlation between the Val/Val variant genotype of MTHFR and various clinicopathological variables in this ethnic Kashmiri population, especially in the older age group. However, these correlations need to be authenticated in a large-sample study in the future, so as to help in better discernment of racial differences and in determining the aggressiveness of colorectal cancer.

\section{CONCLUSION}

Hence, in this study, which has been carried out for the first time in the Kashmir Valley, we observed a significant correlation between the Val/Val variant MTHFR status and various clinicopathological variables in this ethnic Kashmiri population.

\section{ACKNOWLEDGMENTS}

Research supported by the Sher-I-Kashmir Institute of Medical Sciences, Kashmir. We are grateful to the technical staff of the Department of General Surgery for helping in the procurement of tumor tissue samples from the operating room. We also thank the anonymous pathologists of the Department of Pathology for the histopathological assessment of the tumor tissues. 


\section{REFERENCES}

Bagley PJ and Selhub J (1998). A common mutation in the methylenetetrahydrofolate reductase gene is associated with an accumulation of formylated tetrahydrofolates in red blood cells. Proc. Natl. Acad. Sci. U. S. A. 95: 13217-13220.

Bailey LB and Gregory JF III (1999). Polymorphisms of methylenetetrahydrofolate reductase and other enzymes: metabolic significance, risks and impact on folate requirement. J. Nutr. 129: 919-922.

Center MM, Jemal A and Ward E (2009a). International trends in colorectal cancer incidence rates. Cancer Epidemiol. Biomark. Prev. 18: 1688-1694.

Center MM, Jemal A, Smith RA and Ward E (2009b). Worldwide variations in colorectal cancer. CA Cancer J. Clin. 59: 366-378.

Chandy S, Sadananda Adiga MN, Ramachandra N, Krishnamoorthy S, etal. (2010). Association of methylenetetrahydrofolate reductase gene polymorphisms \& colorectal cancer in India. Indian J. Med. Res. 131: 659-664.

Chen J, Giovannucci E, Kelsey K, Rimm EB, et al. (1996). A methylenetetrahydrofolate reductase polymorphism and the risk of colorectal cancer. Cancer Res. 56: 4862-4864.

Chen J, Giovannucci E, Hankinson SE, Ma J, et al. (1998). A prospective study of methylenetetrahydrofolate reductase and methionine synthase gene polymorphisms, and risk of colorectal adenoma. Carcinogenesis 19: 2129-2132.

Cicek MS, Nock NL, Li L, Conti DV, et al. (2004). Relationship between methylenetetrahydrofolate reductase C677T and A1298C genotypes and haplotypes and prostate cancer risk and aggressiveness. Cancer Epidemiol. Biomark. Prev. 13: 1331-1336.

Frosst P, Blom HJ, Milos R, Goyette P, et al. (1995). A candidate genetic risk factor for vascular disease: a common mutation in methylenetetrahydrofolate reductase. Nat. Genet. 10: 111-113.

Haghighi MM, Radpour R, Mahmoudi T, Mohebbi SR, et al. (2009). Association between MTHFR polymorphism (C677T) with nonfamilial colorectal cancer. Oncol. Res. 18: 57-63.

Houlston RS and Tomlinson IP (2001). Polymorphisms and colorectal tumor risk. Gastroenterology 121: 282-301.

Jemal A, Bray F, Center MM, Ferlay J, et al. (2011). Global cancer statistics. CA Cancer J. Clin. 61: 69-90.

Keku T, Millikan R, Worley K, Winkel S, et al. (2002). 5,10-Methylenetetrahydrofolate reductase codon 677 and 1298 polymorphisms and colon cancer in African Americans and whites. Cancer Epidemiol. Biomark. Prev. 11: 16111621.

Kono S and Chen K (2005). Genetic polymorphisms of methylenetetrahydrofolate reductase and colorectal cancer and adenoma. Cancer Sci. 96: 535-542.

Levine AJ, Siegmund KD, Ervin CM, Diep A, et al. (2000). The methylenetetrahydrofolate reductase $677 \mathrm{C} \rightarrow \mathrm{T}$ polymorphism and distal colorectal adenoma risk. Cancer Epidemiol. Biomark. Prev. 9: 657-663.

Lucock M (2000). Folic acid: nutritional biochemistry, molecular biology, and role in disease processes. Mol. Genet. Metab. 71: 121-138.

Ma J, Stampfer MJ, Giovannucci E, Artigas C, et al. (1997). Methylenetetrahydrofolate reductase polymorphism, dietary interactions, and risk of colorectal cancer. Cancer Res. 57: 1098-1102.

Marugame T, Tsuji E, Kiyohara C, Eguchi H, et al. (2003). Relation of plasma folate and methylenetetrahydrofolate reductase C677T polymorphism to colorectal adenomas. Int. J. Epidemiol. 32: 64-66.

Mir MM, Dar NA, Gochhait S, Zargar SA, et al. (2005). p53 mutation profile of squamous cell carcinomas of the esophagus in Kashmir (India): a high-incidence area. Int. J. Cancer 116: 62-68.

Murtaza I, Mushtaq D, Margoob MA, Dutt A, et al. (2006). A study on p53 gene alterations in esophageal squamous cell carcinoma and their correlation to common dietary risk factors among population of the Kashmir Valley. World $J$. Gastroenterol. 12: 4033-4037.

Park KS, Mok JW and Kim JC (1999). The 677C > T mutation in 5,10-methylenetetrahydrofolate reductase and colorectal cancer risk. Genet. Test. 3: 233-236.

Sachse C, Smith G, Wilkie MJ, Barrett JH, et al. (2002). A pharmacogenetic study to investigate the role of dietary carcinogens in the etiology of colorectal cancer. Carcinogenesis 23: 1839-1849.

Saffroy R, Lemoine A and Debuire B (2005). MTHFR (5,10-Methylenetetrahydrofolate reductase) Atlas Genet Cytogenet Oncol Haematol. Available at [http://AtlasGeneticsOncology.org/Genes/MTHFRID41448ch1p36.html]. Accessed 2009.

Salam I, Hussain S, Mir MM, Dar NA, et al. (2009). Aberrant promoter methylation and reduced expression of p16 gene in esophageal squamous cell carcinoma from Kashmir Valley: a high-risk area. Mol. Cell Biochem. 332: 51-58.

Sameer AS, Chowdri NA, Syeed N, Banday MZ, et al. (2010a). SMAD4 - molecular gladiator of the TGF-beta signaling is trampled upon by mutational insufficiency in colorectal carcinoma of Kashmiri population: an analysis with relation to KRAS proto-oncogene. BMC Cancer 10: 300. 
Sameer AS, Shah ZA, Syeed N, Banday MZ, et al. (2010b). TP53 Pro47Ser and Arg72Pro polymorphisms and colorectal cancer predisposition in an ethnic Kashmiri population. Genet. Mol. Res. 9: 651-660.

Shannon B, Gnanasampanthan S, Beilby J and Iacopetta B (2002). A polymorphism in the methylenetetrahydrofolate reductase gene predisposes to colorectal cancers with microsatellite instability. Gut 50: 520-524.

Siddiqi M, Kumar R, Fazili Z, Spiegelhalder B, et al. (1992). Increased exposure to dietary amines and nitrate in a population at high risk of oesophageal and gastric cancer in Kashmir (India). Carcinogenesis 13: 1331-1335.

Slattery ML, Potter JD, Samowitz W, Schaffer D, et al. (1999). Methylenetetrahydrofolate reductase, diet, and risk of colon cancer. Cancer Epidemiol. Biomark. Prev. 8: 513-518.

Ulrich CM, Kampman E, Bigler J, Schwartz SM, et al. (1999). Colorectal adenomas and the C677T MTHFR polymorphism: evidence for gene-environment interaction? Cancer Epidemiol. Biomark. Prev. 8: 659-668.

Wagner C (1995). Biochemical Role of Folate in Cellular Metabolism. In: Folate in Health and Disease (Bailey LB, ed.) Marcel Dekker, New York, 23-42.

Yin G, Kono S, Toyomura K, Hagiwara T, et al. (2004). Methylenetetrahydrofolate reductase C677T and A1298C polymorphisms and colorectal cancer: the Fukuoka Colorectal Cancer Study. Cancer Sci. 95: 908-913. 